\title{
O PROCESSO DE TRABALHO DOS ENFERMEIROS EM UNIDADES DE ALOJAMENTO CONJUNTO PEDIÁTRICO DE INSTITUIÇÕES HOSPITALARES PÚBLICAS DE ENSINO DO PARANÁ
}

\author{
Diane Militão Yamamotoํㅡ, Beatriz Rosana Gonçalves de Oliveira², Cláudia Silveira Viera ${ }^{3}$, Neusa Collet ${ }^{4}$
}

\footnotetext{
${ }^{1}$ Enfermeira. Paraná, Brasil. E-mail: dianeyamamoto@yahoo.com.br

${ }^{2}$ Mestre em Enfermagem Fundamental. Docente do Curso de Enfermagem do campus de Cascavel da Universidade Estadual do Oeste do Paraná (Unioeste). Paraná, Brasil. E-mail: lb.toso@certto.com.br

${ }^{3}$ Doutora em Enfermagem em Saúde Pública. Docente do Curso de Enfermagem do campus de Cascavel da Unioeste. Paraná, Brasil. E-mail: claudiavictor@terra.com.br

${ }^{4}$ Doutora em Enfermagem. Docente do Curso de Enfermagem e do Programa de Pós-Graduação em Enfermagem da Universidade Federal da Paraíba. Paraíba, Brasil. E-mail: neucollet@gmail.com
}

\begin{abstract}
RESUMO: O estudo objetivou compreender o processo de trabalho do enfermeiro em Unidades de Alojamento Conjunto pediátrico com assistência pautada pelo referencial da assistência integral ao binômio família-criança. Pesquisa qualitativa cujos procedimentos metodológicos adotados foram: entrevista semi-estruturada e observação participante. Os dados foram analisados seguindo-se as regras para análise temática. A pesquisa evidenciou que a atuação do enfermeiro na unidade pediátrica, independente das transformações ocorridas em seu processo de trabalho, continua tendo como enfoque principal a patologia da criança e não contempla a prática da assistência centrada no usuário - criança e sua família. Percebe-se que a assistência à díade família-criança fica comprometida ou os mesmos ficam desassistidos pelo profissional enfermeiro, remetendo a uma reflexão sobre o saber-fazer da enfermagem que modifique a forma como o enfermeiro vem desenvolvendo, ao longo do tempo, sua atuação no cuidado à criança hospitalizada e sua família.

DESCRITORES: Enfermagem. Trabalho. Prática profissional. Criança hospitalizada. Família.
\end{abstract}

\section{THE NURSING WORK PROCESS IN THE PEDIATRIC WING OF PUBLIC UNIVERSITY HOSPITALS IN PARANA, BRAZIL}

\begin{abstract}
The purpose of this study was to better comprehend the nursing work process in the pediatric wing with care guided by the reference of integral care for the hospitalized child and his/her family. A qualitative study, the authors used the semi-structured interview and participant observation as methodological proceedings. The data was analyzed according to thematic analysis. This study identified that in spite of the changes that have occurred in the nursing work process, nursing actions in the pediatric unit continue to focus upon the child's illness as opposed to centering upon the child and his/her family. It is perceived that health care for the child and his/her family was compromised or rather they were not taken care of by the professional nurse, causing reason for reflection about knowledge-action in nursing which modifies the manner which the nurse develops over time his/her action in caring for hospitalized children and their families.
\end{abstract}

DESCRIPTORS: Nursing. Work. Professional practice. Child hospitalized. Family.

\section{EL PROCESO DE TRABAJO DEL ENFERMERO EN LA UNIDAD DE PEDIATRÍA DE ALOJAMIENTO CONJUNTO EN LAS INSTITUCIONES PÚBLICAS DE ENSEÑANZA DEL PARANÁ}

RESUMEN: El objetivo de este estudio fue comprender el proceso de trabajo del enfermero en la unidad de pediatría de alojamiento conjunto en lo que se refiere a la atención integral al niño hospitalizado y a su familia. Investigación de carácter cualitativo, cuyos procedimientos metodológicos adoptados fueron: la entrevista semiestructurada y la observación participante. Los datos fueron analizados por medio de las normas del análisis temático. La investigación reveló que las acciones del enfermero en la unidad de pediatría, independiente de los cambios en su proceso de trabajo, sigue centrada en la enfermedad del niño y no se ocupa de la práctica de la atención centrada en el usuario: el niño y su familia. Se percibió que la atención al niño y su familia queda comprometida o ellos quedan sin la atención de los profesionales de enfermería, lo que hace necesaria una reflexión sobre el quehacer de la enfermería para cambiar la forma como el enfermero ha venido desarrollando su labor en el cuidado del niño hospitalizado y de su familia.

DESCRIPTORES: Enfermería. Trabajo. Práctica profesional. Niño hospitalizado. Família. 


\section{INTRODUÇÃO}

Este estudo trata do cotidiano de trabalho dos profissionais enfermeiros sob a ótica do processo de trabalho, no cuidado à criança hospitalizada e sua família. Definimos processo de trabalho como a transformação de um objeto determinado em um produto determinado, por meio da ação humana que, para fazê-lo, emprega instrumentos de trabalho. ${ }^{1}$

As mudanças ocorridas na assistência de enfermagem à criança hospitalizada foram muitas e significativas desde a transformação da legislação, garantindo a permanência dos familiares no hospital durante o tratamento, o que alterou de forma significativa o cotidiano dos profissionais da saúde, principalmente da equipe de enfermagem que permanece maior tempo em contato com a criança e sua família.

No processo de trabalho, a dimensão técnica possibilita apreender o conhecimento do trabalhador sobre seu trabalho. Sabendo quais são os elementos desse processo, o objeto poderá ser transformado no foco da atenção. Seus componentes, então, são os objetos, os agentes, os instrumentos, as finalidades e os produtos.

No processo de trabalho dos profissionais de saúde, estaremos adotando a definição para a qual o objeto de trabalho é o indivíduo ou grupos doentes, sadios ou expostos a risco, que necessitam de medidas curativas, e/ou preventivas e/ou de promoção da saúde. Os instrumentos ou meios de trabalho são as condutas, as tecnologias, o saber em saúde. E o produto final é a própria assistência em saúde, que é consumida no mesmo momento em que é produzida, com a finalidade de obter a ação terapêutica de saúde. ${ }^{2}$

Na Enfermagem há mais de um processo de trabalho, que pode ser, ou não, desenvolvido de forma concomitante. Estes são: o processo de trabalho assistir, o processo de trabalho administrar, o processo de trabalho ensinar, o processo de trabalho pesquisar e o processo de trabalho participar politicamente, sendo que estes não são estanques, se relacionam constantemente e quase sempre simultaneamente. ${ }^{3}$

Cabe ao enfermeiro prestar os cuidados de maior complexidade técnica e que exijam conhecimentos de base científica e capacidade de tomar decisões, bem como administrar, coordenar, supervisionar sua equipe, dentre outros. A enfermagem se organiza utilizando, principalmente, três instrumentos de trabalho: a administração - para organizar o ambiente; as técnicas - para organizar o cuidado; e os mecanismos disciplinares - para organizar seus agentes. ${ }^{2,4}$

A divisão do trabalho de enfermagem é realizada por diferentes modalidades. Na modalidade de cuidados funcionais, o trabalhador de enfermagem (técnico, auxiliar ou atendente) desenvolve um trabalho rotineiro por tarefas, ou seja, há uma repetição de afazeres específicos e desarticulados. Assim, o cotidiano do trabalho é alienante, pois o executor da tarefa se exime do entendimento da totalidade da assistência de enfermagem, a qual, quando baseada nos cuidados integrais, rompe com a divisão das tarefas, responsabilizando os trabalhadores de enfermagem pelo atendimento integral, proporcionando uma visão global das necessidades do usuário, tornando o trabalho potencialmente mais criativo. ${ }^{5}$

A presente pesquisa tem como objeto de estudo o processo de trabalho dos profissionais enfermeiros na assistência a criança hospitalizada. O interesse sobre a temática surgiu após a conclusão da pesquisa realizada anteriormente na unidade de Alojamento Conjunto Pediátrico (ACP) de uma instituição hospitalar pública, com o título - O sofrimento psíquico da equipe de enfermagem na assistência a criança hospitalizada, o qual apontou, dentre outras evidências, a dinâmica do processo de trabalho como o fator de maior relevância no sofrimento psíquico na equipe de enfermagem.

A partir da inserção dos familiares na unidade de internação pediátrica percebeu-se uma alteração na dinâmica de trabalho em função da permanência dos pais na unidade. O cuidado antes prestado unicamente pela equipe de enfermagem agora é compartilhado com os pais, o que leva a equipe a modificar suas ações cotidianas, delegando a família parte do cuidado e por outro lado, desresponsabilizando-se por determinadas ações, tais como alimentação, higiene, conforto. Com a participação da família no cuidado, poderíamos esperar o foco da atenção nos usuários, mas estudos têm demonstrado que esse continua sendo nos procedimentos. ${ }^{5-7}$

Assim, o objetivo deste estudo foi compreender o processo de trabalho do profissional enfermeiro em unidades ACP de hospitais públicos de ensino do Estado do Paraná.

\section{METODOLOGIA}

Para o desenvolvimento do estudo nos fundamentamos na corrente histórico-social, por entender que, como forma de apropriação há sempre que se tomar a realidade e, especificamente, o que acontece 
nas relações sociais e produtivas concretas articulando teoria e prática, por um caminho metodológico que permita uma aproximação do concreto e do todo por meio da mediação das partes. Sem o qual, a produção é parcial e pouco útil para dar suporte às intervenções no sentido da transformação da realidade, em que sujeito e objeto do conhecimento são constituídos reciprocamente. ${ }^{8}$

A pesquisa de campo foi realizada durante o período de dezembro de 2005 a junho de 2007, em três hospitais públicos de ensino do Estado do Paraná. O critério para a escolha dos sujeitos da pesquisa foi ser enfermeiro do ACP e aceitar participar da pesquisa. Participaram do estudo nove enfermeiros, sendo dois da Instituição 1 (INST 1), três da Instituição 2 (INST 2) e quatro da Instituição 3 (INST 3). As técnicas de coleta de dados foram entrevista semi-estruturada e a observação participante, as quais foram realizadas em todos os turnos de trabalho a fim de captarmos a dinâmica de trabalho da unidade e entendermos o fluxo de cuidado da díade criança-família. Os dados da observação foram registrados em diário de campo. As entrevistas foram gravadas e transcritas na íntegra, após autorização dos enfermeiros, a fim de obtermos maior fidelidade dos dados. As questões norteadoras para a apreensão do processo de trabalho foram: Quais são suas atividades no ACP? Qual é seu objeto de trabalho? Quais são seus instrumentos de trabalho? Qual é o produto final de seu trabalho?

A trajetória interpretativa seguiu os passos de ordenação dos dados, classificação dos dados e a análise final. ${ }^{8}$ A partir do conjunto do material empírico produzido, foram feitas diversas leituras horizontais destacando estruturas de relevância nos textos. Realizamos uma leitura vertical dos dados assinalando os aspectos convergentes e divergentes. As leituras cruzadas entre os núcleos de sentido obtidos na análise das entrevistas e nos registros do diário de campo permitiram apreender as categorias empíricas do estudo, denominadas o (des)entendimento do enfermeiro sobre seu processo de trabalho em alojamento conjunto pediátrico e as atividades do profissional enfermeiro na dinâmica do cotidiano no ACP. Nesse momento optamos por apresentar uma síntese da categoria atividades do enfermeiro nos processos de trabalho em ACP, do conjunto de dados obtidos na pesquisa.

O projeto foi aprovado pelo Comitê de Ética em Pesquisa com Seres Humanos da Unioeste sob o parecer $\mathrm{N}^{\circ} 13 / 2005$ e todos os enfermeiros participantes do estudo assinaram o Termo de Consentimento Livre e Esclarecido. Para manter o anonimato dos sujeitos, representamos suas falas pela letra E seguido do número da entrevista entre parênteses (E1).

\section{CARACTERIZAÇÃO DAS INSTITUIÇÕES}

A INST1 está situada na região Oeste do Paraná. O ACP possui uma capacidade de 28 leitos e a equipe de enfermagem é composta por cinco enfermeiras e 23 auxiliares de enfermagem. A segunda e a terceira instituição se localizam ao Norte do Paraná, possuindo respectivamente, 15 leitos com uma equipe de cinco enfermeiras e 13 técnicas e auxiliares de enfermagem e 34 leitos com uma equipe composta por quatro enfermeiras, seis técnicas de enfermagem, 25 auxiliares de enfermagem, 10 atendentes de enfermagem e duas técnicas administrativas. Na terceira instituição é realizada a prescrição de enfermagem informatizada.

Nos três hospitais a criança hospitalizada tem garantido a presença de um acompanhante em período integral, embora em todas as instituições identificássemos condições precárias para a permanência destes no hospital. A família não participa do processo terapêutico sendo, em muitas ocasiões, excluída de qualquer decisão sobre o tratamento. As necessidades dos familiares acompanhantes também não são contempladas na perspectiva do cuidado de enfermagem.

O trabalho realizado pelas equipes de enfermagem contempla a parte técnica do processo de trabalho, sendo composto basicamente por administração de medicamentos, curativos e verificação dos sinais vitais. Já o trabalho do enfermeiro é organizado de acordo com a demanda de tarefas cotidianas que lhe são solicitadas, abrangendo aspectos administrativos, gerenciais e assistenciais.

\section{ATIVIDADES DO ENFERMEIRO NO PRO- CESSO DE TRABALHO EM ALOJAMEN- TO CONJUNTO PEDIÁTRICO}

Os enfermeiros iniciam sua jornada de trabalho mediante o registro formal de sua chegada e dirigem-se as respectivas unidades de ACPs para receber o plantão. Na INST1 o enfermeiro se dirige à sala de enfermagem, fora do $\mathrm{ACP}$, para trocar informações sobre o turno de trabalho e receber o plantão (de forma verbal ou por meio da leitura do livro de ocorrência/plantão do setor). Na INST2, dirige-se à unidade de $\mathrm{ACP}$ e recebe o plantão a beira do leito ou no balcão dependendo do profissional que irá repassar as informações 
e na INST3 indo para a sala de enfermagem da unidade de $\mathrm{ACP}$, e recebe o plantão.

Já na unidade de ACP, as atividades realizadas pela enfermagem são registradas nos impressos disponibilizados pelas instituições, e o registro das atividades do enfermeiro, na maioria das vezes, não é realizado.

A Sistematização da Assistência de Enfermagem (SAE) não é realizada de forma integral, assim, na INST1 a prescrição de enfermagem é inexistente e as atividades realizadas são registradas no livro de ocorrências do setor. Na INST2 há realização da prescrição de enfermagem e evolução (todavia, os diagnósticos de enfermagem não são registrados) sendo anotadas no livro de passagem de plantão as informações que julgam importantes para a continuidade do cuidado. $\mathrm{Na}$ INST3, somente a prescrição de enfermagem é realizada, mas baseada na patologia, utilizam impressos para a passagem de plantão. Ao final do período ao pé do leito ou balcão (INST2), na sala de enfermagem (INST1 e 3), são repassadas as informações do plantão, verbal ou somente pelo registro no livro de ocorrências.

Esse modo de organizar o trabalho assume características de fragmentação da assistência, não havendo coordenação sistematizada no serviço, nem da equipe nem do cuidado. A dinâmica de trabalho observada nas três unidades de ACPs é semelhante. No turno matutino há uma concentração das atividades assistenciais (atividades técnicas). No período vespertino ocorre o maior número de internamentos, ações/resoluções burocráticas e administrativas e no período noturno a manutenção da assistência, sendo a medicação a principal atividade realizada pela equipe de enfermagem neste período.

\section{Atividades administrativas e gerenciais}

A ênfase que os profissionais enfermeiros verbalizaram como abordagem adotada na unidade para o cuidado é a centrada na díade criança-família. Meu foco de trabalho está na criança e na mãe (E8, E9, E6). Esta é a proposta de ACP com abordagem na assistência integral que deve ter como foco a criança doente e a família inserida em um determinado ambiente ecológico, socioeconômico e cultural. ${ }^{9}$ Assim, o cuidado nessa unidade passa a assumir características diferenciadas, pois não somente é atendido o indivíduo hospitalizado, mas à partir da sistematização da assistência são considerados os problemas, interesses, potencialidades e expectativas de toda a família no cuidado à saúde. ${ }^{9}$
A passagem de plantão é uma atividade do enfermeiro, que deve ser entendida como um meio de garantir a continuidade da assistência prestada, constituindo-se fundamental para a organização do trabalho. ${ }^{10}$ Nos hospitais em estudo, os enfermeiros relatam que: a passagem de plantão é verbal e escrita, antes era só verbal, mas como tem muito exame, muitas coisas pra tá lembrando, então instituiu escrevendo também (E1); eu leio as intercorrências, e leio desde a hora que eu saí, da tarde e o da noite e no final vou para a sala de enfermagem passar o plantão (E9).

Embora a comunicação verbal predomine na passagem do plantão, observamos que o encontro diário dos profissionais enfermeiros de cada plantão ocorre esporadicamente. Para realizarem a troca de informações foi estabelecido o registro de todas as ocorrências em um livro de registros/ ocorrências, a fim de amenizarem a ausência de comunicação direta.

As anotações dos profissionais enfermeiros contidas no livro de registro/plantão se limitam a informações como nome do paciente e patologia; e alguns procedimentos realizados (exames diferenciados e/ou procedimento de maior complexidade; observações ou recados sobre algum assunto pertinente como, por exemplo, quebra de materiais, que possam necessitar de reposição, ou problemas na escala de funcionários). Vale ressaltar que estas mesmas informações não são registradas nos prontuários das crianças, sendo este o documento formal de uma instituição hospitalar para registro da assistência de todos os profissionais de saúde.

O foco da passagem de plantão está centrado na patologia e não na assistência integral voltada para a díade. Para tanto, abordagens sobre os aspectos emocionais, psicológicos, dificuldades, problemas relacionados à criança ou qualquer informação considerando a família, não são abordados, com ressalva àquelas situações em que a equipe apresentou algum conflito com a família. Tampouco são considerados os problemas, interesses, potencialidades e expectativas da família no cuidado à saúde.

Outro aspecto identificado é que a passagem de plantão, quando ocorre, é realizada apenas entre os profissionais enfermeiros, sem incluir a equipe de enfermagem, evidenciando que o cuidado é compartamentalizado, podendo ter prejuízos na qualidade da assistência.

Em relação aos recursos materiais, verificamos que há preocupação em prover os mesmo para o bom andamento das atividades da unidade. 
Assim, o enfermeiro [...] vê o que falta na unidade, prevê e provê materiais [...]. A gente vai vendo o que precisa, o que tá faltando, aí a gente solicita, vai no almoxarifado, na farmácia, ou se não tem a gente faz uma solicitação e encaminha pra chefia (E8). Toda terça-feira é feita a solicitação de material de almoxarifado, então é o enfermeiro que faz, essa necessidade (E2).

Cabe destacar que a falta de materiais e medicamentos é freqüente nas instituições em estudo e a quantidade enviada para reposição não é suficiente para a realização das atividades previstas. Ou ainda, a qualidade desses materiais compromete a assistência. Assim, os funcionários solicitam e se deslocam para buscar os materiais, ou recorrem a empréstimos em outras unidades. Há, além disto, aqueles que utilizam sua criatividade para desenvolver a assistência, porém não como uma ação desencadeadora do ato criar, mas sim de improvisar materiais para a realização do trabalho. Isto tem gerado insatisfação, angústia e ansiedade como resultado da desmotivação no trabalho, levando o trabalhador a fazer o mínimo necessário para a assistência da criança e família, que busca a integralidade. ${ }^{11}$

A sobrecarga de atividades dos enfermeiros está presente no cotidiano observado, cuja organização do trabalho, em geral, está pautada na prescrição médica. A prática da enfermagem é subordinada a prática médica, pois a sua natureza é definida a partir do trabalho deste, e a posição funcional das suas tarefas é determinada de acordo com a centralidade das tarefas médicas. ${ }^{12}$

No cotidiano do grupo observado, identificamos que uma das primeiras ações dos enfermeiros é olhar a prescrição médica, os pedidos de exames e a preocupação em preparar os materiais para um determinado procedimento médico. Quando ficam prontas as prescrições médicas, também eu tô ali coordenando as prescrições médicas, colocando horário, quando não, as meninas já colocaram, mesmo assim a gente dá uma checada (E1). [...] a criança interna, ela veio de veia ou já tá prescrito avaliação do cirurgião, eu já chego e deixo o material pronto, eles não têm paciência de esperar, eu já deixo o material pronto, a hora que o doutor chega, ele vai lá, avalia a criança, mas pra fazer flebo a criança tem que ter veia pega, nem que for uma 22 (E9).

Nas observações podemos confirmar que os enfermeiros têm se baseado nas ordens médicas, dependentes da prescrição médica para orientar suas ações e da equipe de enfermagem. A organização da assistência, portanto, está centrada na patologia e em procedimentos e não na assistência integral à criança-acompanhante.
Oenfermeiro é solicitado por outros profissionais da equipe de saúde somente quando estes não conseguem implementar a prescrição médica ou realizar algum procedimento técnico. ${ }^{13}$ Aqui a gente tem que ler prescrição, [...] porque às vezes tá escrito $25 \mathrm{ml}$ de uma medicação e a criança tem 10 anos, porque quem prescreve é o acadêmico. A doutora só passa na avaliação [...] aí eu tenho que tá fazendo (E9). Ao atender a essas demandas, a enfermeira lia a prescrição médica e ia identificando o problema, dialogando com os acadêmicos de medicina ou com seus professores. Após, comunicava à equipe as mudanças na prescrição, demonstrando que as ações de enfermagem são dependentes da prescrição médica.

Embora a assistência direta às crianças e suas famílias esteja subliminar no trabalho do enfermeiro, ele tem ocupado papel importante na organização de um trabalho coletivo que depende da coordenação de atividades as quais reúnem o conhecimento e as habilidades técnicas, interdisciplinares, para alcançar os objetivos assistenciais desejáveis. ${ }^{14}$

Outra atividade realizada pelos enfermeiros é a SAE. Nas INST2 e 3, os enfermeiros afirmaram utilizá-la como rotina na unidade para viabilizar a organização do trabalho, bem como pelos benefícios que este processo reflete na assistência prestada pela equipe de enfermagem e na INST1 os enfermeiros afirmaram não utilizar a SAE. Eu sempre sento para escrever em torno das 11 hs para evoluir as crianças no prontuário, fazer prescrição. Das 11hs às 13hs da tarde eu fico em função de prontuário e tudo e tal, prescrevendo, evoluindo e escrevendo a passagem de plantão (E3).

Nas instituições do estudo que implementavam a SAE, para a realização das prescrições e evoluções havia instrumentos impressos, os quais eram utilizados sempre que os enfermeiros iniciavam o processo. Estas eram realizadas de acordo com as necessidades da criança, apreendidas pelo profissional enfermeiro, que viabilizavam as ações da equipe de enfermagem no desenvolver do cuidado a criança. Acreditamos que o gerenciamento do cuidado de enfermagem é o papel do enfermeiro como agente desencadeador do processo de trabalho em enfermagem, pois possibilita exercer a administração da assistência de forma global, coerente e responsável, vendo o usuário em sua totalidade e contemplando o cuidado integral.

A gente revê as prescrições, vê todos os cuidados que precisam acrescentar, tirar, aí imprime, abro as prescrições e o pessoal da noite vai dar uma revisada, se tem que mexer, [...], a partir disso decido que prescrição que eu vou fazer (E5). Em uma das instituições, 
havia um enfermeiro diretamente responsável por efetuar as prescrições de enfermagem. Embora verbalizado por este, afirmando o cumprimento da tarefa, durante o período de observação, não identificamos que ele de fato tenha desenvolvido esta atividade, pois seu trabalho estava centrado nos procedimentos para internamentos e nas questões burocráticas.

A evolução de enfermagem que deveria ser realizada pelo profissional enfermeiro não foi observada, bem como, somente as anotações das atendentes, auxiliares e técnicas foram identificadas no instrumento utilizado para o plano de cuidados diários/prescrição de enfermagem. Tampouco o prognóstico de enfermagem era anotado e/ou registrado.

Observamos nos dois campos em que ocorre a SAE que naquele em que há divisão de leitos entre os enfermeiros para o planejamento do cuidado, a assistência é pautada pelos princípios de acolhimento, vinculação e responsabilização, pois o enfermeiro realiza a anamnese, o exame físico, o levantamento de problemas, a prescrição de enfermagem e a avaliação do cuidado. Diferentemente do campo em que um único enfermeiro desenvolve as prescrições para todas as crianças, pois este trabalha com o foco na prescrição médica e os cuidados de enfermagem emergem a partir do diagnóstico médico, não realiza as etapas de identificação dos diagnósticos de enfermagem, ou seja, sem contato com a díade criança-mãe. No planejamento da assistência de enfermagem ${ }^{14}$ salienta-se que o maior obstáculo da enfermagem como profissão é o fato de que a maioria do que é dito e feito através dela fica fora de qualquer tipo de documentação escrita, portanto, não será contabilizada ou mesmo reconhecida.

Na INST1, aSAEnão é realizada. A justificativa verbalizada por alguns enfermeiros seria a sobrecarga de trabalho imposto pela demanda que é grande. Quando vejo já ta na hora de fazer o relatório (E8). [...] sento e faço o relatório (E9). Deste modo, o enfermeiro registra suas atividades no livro de registro/plantão, mas este não tem valor legal, refletindo na não valorização e reconhecimento deste profissional.

O profissional enfermeiro deixa de desempenhar atividades de sua competência, para as quais foi preparado, não garantindo uma definição e determinação de seu próprio espaço, limitando-se ao que lhe é atribuído pela administração superior ou por outros profissionais. ${ }^{13}$

Em relação às atividades gerenciais do enfermeiro identificamos que o mesmo organiza a escala de funcionários prevendo e provendo pessoal para todos os turnos de trabalho: [...] vejo se tem alguém de folga na escala (E5); [...] verifico a escala de funcionários (E7); [...] tem que ver a escala de férias, isso depende muito da época do mês (E4); viabiliza e dinamiza os internamentos, sendo esta uma atividade que demanda muito tempo do enfermeiro: Primeiro lugar, vou ver é sobre as vagas. Quais são as vagas que tem, porque logo o moço da internação começa a ligar e você tem que tá pronta (E7); viabiliza procedimentos e encaminhamentos para a alta hospitalar da criança.

No cotidiano da assistência os enfermeiros apresentaram um trabalho rotineiro. Em suas ações gerenciais e administrativas predominam o trabalho hierarquizado e obediente as ordens institucionais, ou seja, viabilizar o trabalho médico. Durante a coleta de dados observamos que a maior parte do tempo o enfermeiro realiza preferencialmente tarefas relativas à administração e gerenciamento, ao invés do cuidado à díade criança-família.

\section{Atividades assistenciais}

O produto final do processo de trabalho dos profissionais de saúde é a própria prestação da assistência que é produzido no mesmo momento em que é consumido. ${ }^{2}$ Nesta perspectiva temos, nas falas de todos os enfermeiros, que a prioridade em seu trabalho em ACP é a assistência à díade criança-família. A prioridade é, primeiramente, a assistência dos pacientes, não podendo esquecer das mães/ acompanhantes (E9).

A ordem de prioridades para estabelecer o início das atividades assistenciais ocorre de acordo com as demandas da família. Ficamos no setor ali no posto de enfermagem e as mães que necessitam de alguma coisa estão ali requisitando até umas 8 hs mais ou menos (E1).

Os enfermeiros iniciam seu trabalho diário com uma conversa informal com os demais membros da equipe de enfermagem. Logo após realizam as divisões de trabalho entre a equipe, para então começar a atender as demandas que surgem. Deste modo, durante o período em que ficam no posto de enfermagem, os enfermeiros atendem não somente às mães, mas também aos funcionários e a outros profissionais da saúde, assim como organizam os materiais necessários para a execução da assistência.

Posterior ao primeiro momento de organização da unidade, ocorre a conversa entre a equipe e um grupo de enfermeiros inicia a rotina a partir das 
prioridades que, segundo as falas, são determinadas a partir da passagem de plantão. Na hora que vocêpega plantão a própria equipe já vai determinar para vocêo que vocêvai priorizar, porque se uma colega minha me passar que há um paciente mais instável, é óbvio que eu vou começar com aquele paciente. Se não tiver nada disso eu vou começar pela rotina mesmo [...] eu começo do quarto 1, eu vou examinar paciente por paciente (E4).

Portanto, percebemos que a assistência é planejada e desenvolvida a partir de duas ações predominantes: os pacientes mais instáveis são priorizados; e então são iniciados os cuidados assistenciais a partir das visitas aos quartos, por ordem numérica crescente das enfermarias. Eu começo do quarto 1 eu vou examinar [...], vou ver paciente por paciente (E2); a visita nos outros quartos geralmente começo pelo 1 e assim vai até o último quando dá tempo (E7). Contudo, durante a observação identificamos que nem sempre essa visita ocorre em todos os quartos, pois o enfermeiro é solicitado para realizar outros procedimentos ou atender alguma intercorrência. Assim, o trabalho é organizado de acordo com as demandas que vão aparecendo no cotidiano.

$\mathrm{Na}$ maioria das instituições hospitalares não há coordenação da assistência prestada pelos diferentes grupos de profissionais da saúde. ${ }^{2} \mathrm{No}$ caso da equipe de enfermagem, isto resulta na falta de continuidade da assistência, em decorrência da falta de planejamento da assistência, ou seja, com a falta da sistematização da assistência de enfermagem o trabalho acaba sendo fragmentado ao invés de ser complementar.

A respeito dos procedimentos técnicos realizados pelos enfermeiros houve a predominância dos seguintes itens: exame físico, avaliação dos pacientes, curativos, soroterapia e medicação, verificação das condições hemodinâmicas, oxigenioterapia, coleta e auxílio de exames. Eu passo quarto por quarto visitando as crianças, é um breve exame físico, muito rápido, avalio a criança, a punção, questiono a mãe de como a criança passou a noite, como que tá e ali a gente já começa a se inteirar do que tá acontecendo, de repente se está acontecendo alguma coisa a mãe já passa pra mim e eu vou tentando resolver os problemas [...] e fico na assistência mesmo, vou fazer curativos, puncionar veia, essa é minha rotina (E8).

Cabe aqui ressaltar que, quando estes profissionais se referem ao exame físico, o que observamos foi uma breve observação das crianças, feita no ato da visita e que consiste em um diálogo com crianças e acompanhantes, resumindo-se a perguntar como estavam; como passaram a noite; como estava a alimentação; bem como, a verificação da oxigenioterapia em curso; a validade da sonda nasogástrica e da punção venosa. Essas avaliações são parciais, não fazendo parte do contexto do exame físico nem da anamnese necessária para o levantamento de problemas com vistas ao diagnóstico e prescrição de enfermagem.

A gente sempre procura ir às 8 hs para o quarto, verifica sinais, vai organizando o banho, começa a avaliação, faz exame físico, faz curativo (E1); dependendo da necessidade também faço o exame físico dessas crianças, e os procedimentos de alta complexidade, por exemplo, agora nós temos a troca de NPT, o enfermeiro faz curativos mais complexos, e dependendo do número de funcionários a gente acaba fazendo medicação, troca dos curativos mais simples, banho nas crianças, [atividades] de menor complexidade (E3). Deste modo, durante a visita aos pacientes esses enfermeiros conversam com todos e organizam os cuidados que devem ser realizados no decorrer do plantão. Acompanham, também, as condições hemodinâmicas e/ou realizam as punções venosas e diariamente, na visita nas enfermarias, verificam a validade da mesma. Observam ainda a administração de medicação e de hemoderivados, fixação de cateter central, avaliação de cateter central de inserção periférica e manutenção da bomba de infusão.

Em outra instituição, as atividades predominantes dos enfermeiros eram a coleta de exames, punção venosa e avaliação nutricional. Uma e meia o laboratório chega para colher as gasometrias, aí quem colhe tudo sou eu, ai eu passo de quarto em quarto, vejo punção, olho o equipo se tá vencido, vejo as prioridades das crianças, se a criança tá com diarréia ou não, e daí depois que eu fiz tudo isso aí é hora de medicar, eu já vou dando uma avaliada nas crianças, se ela tá emagrecida, se é criança baixo peso, [...] porque não tem como eu fazer exame físico em cada criança (E9).

Na conversa com o acompanhante, quando este relatava que a criança não estava aceitando a dieta, eram solicitados alimentos diferenciados de acordo com o gosto da criança. Este procedimento foi verificado em todas as instituições pesquisadas. Nos cuidados gerais referentes à alimentação deve estar a relação entre o meio ambiente em que ela se encontra (ambiente hospitalar), sua faixa etária e hábitos alimentares da família. ${ }^{15}$

A assistência direta ao paciente com a realização das atividades técnicas não foi observada com relevância na INST3. A presença de mais de um enfermeiro no setor durante o mesmo plantão, muitas vezes direcionava um para a assistência (normalmente era o residente de enfermagem) e ou- 
tro para as atividades administrativas e gerenciais do setor (o enfermeiro responsável pela unidade). Apesar dessa divisão, quando a unidade estava com sua capacidade máxima, encontramos o enfermeiro da unidade presente na assistência. Porém as atividades mais observadas foram à visita aos quartos e alguns procedimentos como, por exemplo, a manutenção da oxigenioterapia de pacientes mais graves, ou quando solicitado pelo funcionário para acompanhar algum procedimento.

A enfermagem, especialmente o enfermeiro, deve conscientizar-se do papel atual que vêm exercendo e de sua importância no conjunto de ações de saúde. ${ }^{14}$ Assumir a administração da assistência como papel fundamental de sua existência profissional, de direito, exercendo de forma explícita porque se constitui não em um fim determinado pela administração, e sim em meio e instrumento para alcançar a adequada assistência a díade criança-família.

Nesse processo, a família deve ser envolvida na assistência a criança e, ao mesmo tempo, fazer parte da perspectiva do cuidado de enfermagem. Para tanto, instrumentos de trabalho como a interação efetiva, o vínculo e responsabilização devem pautar a organização do processo de trabalho. ${ }^{16}$

A interação é percebida pelos enfermeiros como importante, mas vinculada a um caráter instrumental do trabalho. A gente chega na enfermaria, tenta interagir todo mundo, tenta conversar com todos no sentido de todos entenderem a necessidade de estar usando o avental, de tá se protegendo com relação a aparência física (E1); então a gente tenta colocar todo mundo na situação de acompanhante, na situação de responsável pela criança, trazer eles para essa realidade, que é o objetivo deles aqui dentro do hospital (E2).

O relacionamento da equipe-família inicia no ato da internação, quando as informações sobre a rotina da unidade são colocadas à família. A partir disto, a equipe espera a cooperação da família, ou seja, que ela continue a prestar os cuidados que são realizados no domicílio. Porém, não identificamos, durante as observações, que essas responsabilidades fossem referidas ao familiar, ou questionado se o mesmo teria condições de realizá-las. A posição da família no contex to do cotidiano vivenciado no ambiente hospitalar é de subordinação, de obediência em relação à posição de poder/saber da equipe de saúde. Contudo, a família espera que a equipe assista seu filho, a oriente, a informe e tire suas dúvidas. O que nem sempre é feito pelo enfermeiro.

Embora os enfermeiros tenham verbalizado que a assistência esteja centrada na díade criança- família, identificamos nas observações que em raros momentos a família era contemplada no cuidado. Tampouco é solicitada sua participação nas decisões sobre o plano de cuidados e execução da assistência, a exemplo de estudo anterior realizado em unidade de terapia intensiva neonatal. ${ }^{17}$ Nas ações assistenciais diretas a família, observamos as orientações sobre procedimentos rotineiros da unidade (medicação, punção venosa, nebulização, exame, cirurgia), sendo estas, quando o acompanhante estava em estado emocional abalado, como forma de tranqüilizá-lo.

\section{CONSIDERAÇÕES FINAIS}

Apreendemos na compreensão dos enfermeiros sobre seu processo de trabalho, que os mesmos têm dificuldades em correlacionar suas ações com o processo de trabalho em saúde e na identificação dos elementos desse processo. Por não refletirem sobre seu fazer cotidiano, não visualizam a finalidade de seu trabalho, e não conseguem pensar nas necessidades que deveriam gerar ações e atividades para obter seu produto final e o seu fazer profissional. Isto está diretamente ligado ao modo de produzir da sociedade capitalista, em que ocorre a exploração acentuada da força de trabalho de enfermagem, tornando seu trabalho alienante.

Como objeto do processo de trabalho, encontramos tanto a díade criança-família como a não identificação do objeto de trabalho pelo enfermeiro que atua no ACP. Na apreensão dos meios e instrumentos utilizados para transformar o objeto, os enfermeiros tiveram dificuldade para identificar estes instrumentos. Isto dificulta a perspectiva de uma mudança no trabalho, pois a reflexão da mediação entre o instrumento e o objeto permite ao trabalhador identificar as características em suas ações e no resultado delas, de modo que possa correlacionar com a finalidade inicialmente almejada.

Na ausência da compreensão desses elementos - do seu fazer diário - os enfermeiros não apreendem para quem, como e porquê o cuidado em saúde ou a assistência de enfermagem deve ser realizada. Isto resulta numa prática não planejada, aleatória, de satisfação de demandas momentâneas por seu serviço, e centrada em procedimentos.

As formas de organização e divisão do trabalho de enfermagem evidenciaram a supremacia do modelo clínico, centrado no profissional médico, curativo e individualizado. As intervenções de enfermagem sistematizadas por alguns passos da 
SAE são caracterizadas pela dependência da prática médica. Assim, a assistência a díade criançafamília fica comprometida ou os mesmos ficam desassistidos, remetendo à necessidade de reflexão sobre o saber-fazer da enfermagem no cuidado à criança hospitalizada e sua família.

Nesta dinâmica, as relações que vão sendo estabelecidas são conflituosas e surgem situações complexas a serem enfrentadas, apontando para mudanças mais amplas e coerentes na nova dinâmica do processo de trabalho. Salientamos ser esta uma questão bastante complexa que requer discussão permanente e aprofundada, a fim de vislumbrar caminhos que apontem a interdependência do cuidado no cotidiano da prática assistencial. Nisto se constitui o devir histórico do complexo das relações que envolvem os modos de assistir a criança hospitalizada. Essas mudanças, necessárias no modelo assistencial vigente, devem ter como pressuposto novas formas de produzir o cuidado e mudança de atitude dos enfermeiros em relação às crianças e suas famílias.

Sabemos que todo resultado de pesquisa é provisório e novos estudos sobre a temática precisam ser feitos e aprofundados. Em especial a delimitação do conceito cuidado como objeto do trabalho da enfermagem bem como o papel do profissional enfermeiro no desafio de introduzir a família na promoção, a manutenção da saúde, e como desenvolver suas potencialidades no cuidado à criança, são pontos que merecem ser considerados em estudos futuros.

\section{REFERÊNCIAS}

1. Marx K. O Capital: crítica de economia política, o processo de produção do capital. $24^{\mathrm{a}}$ ed. Rio de Janeiro (RJ): Civilização Brasileira; 2006.

2. Pires D. A estrutura objetiva do trabalho em saúde. In: Leopardi MT, Capella BB, Faria EM, Pires DEP, Kirchoff AL, Ramos FRS, et al. Processo de trabalho em saúde: organização e subjetividade. Florianópolis (SC): UFSC- Papa- livros; 1999.

3. Sanna MC. Os processos de trabalho em enfermagem. Rev Bras Enferm. 2007 Mar-Abr; 60(2):221-4.
4. Lunardi Filho WD; Leopardi MT. O trabalho da enfermagem: sua inserção na estrutura do trabalho geral. Rio Grande (RS): GRAFURG; 1999.

5. Gomes GC, Lunardi Filho WD. A família na unidade de pediatria: uma unidade que se cuida, uma unidade a ser cuidada. Texto Contexto Enferm. 2000 Mai-Ago; 9(2):28-38.

6. Collet N, Rocha SMM. Criança hospitalizada: mãe e enfermagem compartilhando o cuidado. Rev Latinoam Enfermagem. 2004 Mar-Abr; 12(2):191-7.

7. Lima RAG, Scochi CGS, Kamada I, Rocha SMM. Assistência à criança com câncer: alguns elementos para a análise do processo de trabalho. Rev Esc Enferm USP. 1996 Abr; 30(1):14-24.

8. Minayo MCS. O desafio do conhecimento: pesquisa qualitativa em saúde. $10^{\mathrm{a}}$ ed. São Paulo (SP): HucitecAbrasco; 2007.

9. Elsen I, Patrício ZM. Assistência a criança hospitalizada: tipos de abordagem e suas implicações para a enfermagem. In: Schmitz EM. A enfermagem em pediatria e puericultura. Rio de Janeiro (RJ): Atheneu; 2000.

10. Siqueira ILCP, Kurcgant P. Passagem de plantão: falando de paradigmas e estratégias. Acta Paul Enferm. 2005 Out-Dez; 18(4):446-51.

11. Beck CLC. O sofrimento do trabalhador: da banalização a re-significação ética na organização da enfermagem. Florianópolis (SC): UFSC; 2001.

12. Almeida MCP, Rocha SMM. O trabalho de enfermagem. São Paulo (SP): Cortez; 1997.

13. Pivotto F, Lunardi Filho WD, Lunardi VL. Prescrição de enfermagem: dos motivos da não realização às possíveis estratégias de implementação. Cogitare Enferm. 2004 Jul-Dez; 9(2):32-42.

14. Lunardi Filho WD, Lunardi VL. Uma nova abordagem no ensino de enfermagem e de administração em enfermagem como estratégia de (re)orientação da prática profissional do enfermeiro. Texto Contexto Enferm. 1996 Jul-Dez; 5(2):20-34.

15. Collet N, Oliveira BRG. Manual de enfermagem em pediatria. Goiânia (GO): AB; 2002.

16. Merhy EE, Onocko R. Agir em saúde: um desafio para o público. $2^{\text {a }}$ ed. São Paulo (SP): Hucitec; 2002.

17. Oliveira BRG, Lopes TA, Viera CS, Collet N. O processo de trabalho da equipe de enfermagem na UTI neonatal e o cuidar humanizado. Texto Contexto Enferm. 2006; 15(Esp):105-13. 